\title{
ACCESS TO CARE IN A PLURAL HEALTH SYSTEM: CONCERNS FOR POLICY REFORMS \\ M C Weerasinghe ${ }^{1}$, D N Fernando ${ }^{2}$
}

\section{Abstract}

\section{Objectives:}

To examine accessibility to first contact healthcare in rural Sri Lanka in terms of physical proximity to service provider and out of pocket cost on such services in order to provide insights for future policy directions.

\section{Methodology:}

A community based and an institutional based survey was carried out in a rural district. A total of 1200 households were included in the community survey and 2221 patient encounters in both western and Ayurveda / traditional medical facilities were selected for institution based survey. Data was collected from the chief female occupant of the household and patients in the health institutions using an interviewer administered questionnaire.

\section{Results:}

On average all possible healthcare facilities were located within $6 \mathrm{~km}$ of a household while most frequently visited facility indicated bypassing of a closer facility. Cost of seeking treatment from private facilities was over 7 times higher than the state facilities, less than $5 \%$ utilized of non western healthcare facilities .

\section{Conclusion:}

Physical proximity of facilities to the households and free of charge services of state health services may not guarantee their utilization. There is also a possibility of disappearance of plural nature of the health system in Sri Lanka giving away to a single dominant system.

\section{Key words:}

Sri Lanka, Accessibility, Plural medicine, Health system, Health seeking

\section{Introduction}

This paper examines access to first contact healthcare in rural Sri Lanka in terms of physical proximity to service provider and out of pocket costs incurred on such services in order to provide insights for future policy directions. Determining the access to healthcare services in a plural health system raises many questions. 1. Does availability of facilities close to the household grantee that the community uses them? 2. Does the availability of free of charge services in close proximity shift communities away from private healthcare providers? 3. Is affordability a concern when using state healthcare services claimed to be free of charge? 4 . Does the availability of different modalities of treatment improve the access to care? Health seeking behavior of a rural district in Sri Lanka was examined to explore these concerns.

Sri Lanka is known to be a country with a plural health system where western style medical practice coexists with Ayurveda, Unani, Sidha, indigenous forms of treatment along with many ritualistic healing practices (1-3). Sri Lanka is spending US\$42 per capita on health where total expenditure on health is $4.1 \%$ of the GDP (4). The state provides about $49 \%$ of this amount, and the rest is accounted for by non governmental funds. Over $90 \%$ of the non government funds comes from out of pocket expenditures of households. The trends in financing the health sector further indicate that the share of out of pocket expenditure is rising annually, surpassing $50 \%$ of the total health expenditure of the country (4). Although Sri Lanka is better off than some least developed countries that spend US\$ 11 per capita on health, its health expenditure is lower than the middle income countries that spend US\$ 93 on the same (5). As Nichter (6) pointed out, multiple therapy systems and diversity of health behavior patterns being norm for many countries, resource allocation becomes further complicated in a plural setup. Hence, understanding the plural nature of Sri Lankan healthcare arena is fundamental for effective planning.

The Western medicine system was introduced to Sri Lanka under colonial rule after 1500A.D. and has since become the main mode of healthcare in the country (2). It comprises both state and private sector establishments. Ministry of Health is operating the state sector healthcare services through a chain of hospitals and many agencies working on preventive and promotive care. First contact care services are provided through out patient departments (OPD) in the hospitals and dispensaries and those services are claimed to be free of charge at the point of delivery (7). Private sector western healthcare services comprise few hospitals mainly located in urban centers and many private dispensaries operated by western trained practitioners around the

1. Senior Lecturer, Department of Community Medicine, Faculty of Medicine, University of Colombo.

2. Professor of Community Medicine, Department of Community Medicine, University of Colombo. Correspondence : manujchri@yahoo.com 
country. Government doctors have the privilege of doing private consultations in after working hours and the private sector mainly operates through those part time private practitioners.

There is a separate ministry to develop the indigenous medical systems in the country. According to the Ayurveda Act of 1961, Ayurveda includes all the medical systems indigenous to Asian countries and recognized as such by respective governments (8). There is a chain of state hospitals and dispensaries around the country that provides Ayurveda/traditional medical care. There are many private Ayurveda/ traditional practitioners functioning around the country on their own. Some of them are registered with the department of Ayurveda with formal qualifications while others continue their ancestral traditions of healing that had existed for generations (9). Although there is no formal system to register or recognize ritualistic healers, they exist in most of the villages around the country and practice as healers in conjunction with their primary task of acting as spiritual middle man between variety of deities and human beings (10-12).

The information on how physical proximity to facilities and expenses incurred influence the selection of healthcare facilities is vital for decisions on effective resource allocation in development and expanding of health services to peripheral areas of the country. This need is further emphasized by the strategic framework proposed to improve health sector in the country for the next decade (13). Hence, this study focused on accessibility in terms of physical proximity to service provider and out of pocket expenditure on healthcare in a rural district in Sri Lanka.

\section{Methods}

The study employed both a community based household survey and an institutional based survey in the rural sector of the Kegalle District in Sri Lanka. This approach enabled answers to two dimensions of the research question: the community survey focused the physical proximity of healthcare facilities to households while institutional survey inquired the expenses incurred in utilizing such facilities.

For the community based survey, the sample was selected to represent the households in the rural sector of the district of Kegalle. The 'household' was identified as the study unit and was defined as members of a family residing in that housing unit for more than six months duration. Usage of western medical facilities by households was the key variable in calculating the sample size. As this proportion varies for different illnesses and as a satisfactory estimate was not available in the literature, 0.5 was used as the proportion of households using western medical facilities in an illness episode to maximize the sample size (14). In addition, to minimize a design effect in multistage sampling 2 was used as the correction factor in calculating final sample size (15). The sample size was 1200 households which were selected using a multistage probability sampling method. The staging was done according to the hierarchy of administrative structure of the district. A district comprises of several Divisional Secretary (DS) areas while a DS is divided into several dozens of Grama Niladari (GN) divisions which are the smallest administrative units. There are several censes blocks in a GN division. In stage one, five out of 11 DS areas of the district were selected according to Probability Proportionate to Size (PPS). In the second stage 50 out of $324 \mathrm{GN}$ divisions in five DS divisions were selected using PPS. In the next stage, two census blocks of each GN division was selected by simple random sampling. Household lists of the census block prepared for the 2001 census were used as the sampling frame to select the households within each census block. Twelve households from each census block were chosen according to systematic sampling. Thus, twenty four households were selected from each GN division. The Chief female occupant of the household, defined as an adult female in the household who is considered by the other members of the household to be the key female member involved in decisionmaking was identified as the respondent for the study.

For the institutional based survey, the study population was identified as patients attending first contact medical care facilities in the state and private sector institutions providing Western and Ayurveda/ traditional medical care in the Kegalle district.

Patients who were residents of the rural sector of Kegalle district for a minimum of six months and attending out patient department of that particular institution for the first time during the current illness episode were included in the sample. When the study unit was a child below the age of 15 years or the patient was physically not fit, or not mentally sound to decide on the treatment action the information was obtained from the guardian. Two stage stratified random sampling method was used to select the state sector institutions in both western and Ayurveda. In the first stage institutions were stratified according to the Ministry of Health classification (7). Institutions were selected randomly from, each stratum. In the second stage $10 \%$ of patents attending the Western OPD facilities and $30 \%$ attending Ayurveda facilities for the first time for an illness episode during a week were identified from each institution. Patients were selected using systematic sampling. The number of patients to be included in the sample from each institution was decided using the average out patient department attendance per week in the previous year. A higher percentage of patients attending Ayurveda were selected in order to compensate for the low numbers attending those facilities for treatment.

There was no formal system of registration for private medical practitioners. Hence, lists of private 
practitioners of both Western and Ayurveda/traditional were prepared with the help of the field-level health staff of the district to be used as sampling frames. Private sector facilities were restricted to 10 Western practitioners and eight Ayurveda / traditional practitioners due to financial and logistic constrains. They were randomly selected from the list prepared by field staff. As satisfactory records on patient attendance were not maintained in private facilities, every third patient attending to a clinic session and confirming to the eligibility criteria was enrolled into the study.

Eight state-western healthcare institutions, four stateAyurveda healthcare facilities, ten western private practitioners and eight private-Ayurveda/ traditional practitioners were included in the sample of institutions selected for the study. In all institutions/ practitioners, three clinic sessions were surveyed. Altogether, two thousand two hundred and twenty one patients attending 90 clinic sessions in 30 institutions/practitioners were included.

Interviewer administered questionnaires were used as data collecting instruments. In the household survey the respondent was asked the distances and the time taken to reach the closet healthcare provider. The questionnaire inquired information regarding utilization of five categories of healthcare providers namely, state and private western type care providers, state and private Ayurveda / traditional care providers and ritualistic healer. The most frequently visited healthcare facility by the family members during the preceding six months was also inquired.

In the institutional survey, out of pocket cost for the visit for healthcare provider was inquired from each patient. The information was collected on transport costs, provider's fees, additional costs on investigations, additional costs on drugs /supplies and incidental costs for the visit. Transport costs included two way costs to and from the healthcare facility and when applicable to the accompanying person/s. The median for each component of the costs were calculated considering the number of patients who had to bear that specific cost on the visit to the healthcare provider. The total cost for the visit was calculated by accumulating the component costs of each patient and presented as per capita out of pocket cost for a selected type of healthcare facility.

\section{Results}

Household survey

The results of the household survey are given in the Table 1. On average ritualistic healer was the closest to the household while state Ayurveda facility was most distantly placed. As expected from the distance, ritualistic healer could be reached in least time while state Ayurveda facility took the longest time to reach. Furthermore, on average all possible types of healthcare services were located within six kilometers of households and that a free of charge state facility was within five kilometers. All types of facilities could be reached on average within 0.69 hours (42 minutes) of travel from the household.

When the respondents were asked about the most frequently visited healthcare facility by the family members during the preceding six months, 65.5\% indicated that it was state western facility while $29.5 \%, 1.3 \%, 1.2 \%$ and $0.2 \%$ attended private sector western healthcare provider, private Ayurveda / traditional provider, state Ayurveda facility, and ritualistic healer respectively. Rest of the householders had not attended any of the facilities during the six months period. Table 2 shows the distance traveled to the most frequently visited healthcare facility during the preceding six months. Most frequently visited facility by the households indicated that they had chosen a more distantly located one than the nearest available facility. This was common to all types of healthcare facilities. Although the numbers were small, for private Ayurveda / traditional it was twice the distance for the nearest while it was as much as three times for ritualistic healer. In private western facility they had traveled 1.7 times the nearest facility and state western facility it was close to 1.3 times.

\section{Institutional survey}

The findings on cost incurred by patients for the visit are presented in Table 3. Seeking treatment in private facilities in western and Ayurveda systems were 8 times and 7 times higher when considering median costs than using the state sponsored free healthcare services. The cost incurred for provider fees stands out as the highest expenditure for a visit in the private sector in both western and Ayurveda/ traditional systems. In addition, median costs of all other components were also high in private healthcare services compared to state facilities. No investigations were ordered in the Ayurveda/traditional facilities.

\section{Discussion}

Health facilities of all types were available in close proximity to households. In addition, the householders were aware of these facilities. The findings in this study pertaining to geographical access were consistent with two previous studies done in Sri Lanka, namely Manpower in health sector 1975 (16) and Health strategy and financing survey 1992 (17). Considering the limited resources at disposal for the state in managing the health of the people in a less developed country, the availability of healthcare facilities in such proximity to household would be viewed as outstanding. Substantial improvements in the health indicators of Sri Lanka during the last four decades (7) would provide evidence for improved geographical access to health care.

Although the physical proximity to heath facilities was viewed as satisfactory, the utilization pattern raised several concerns. The findings suggest that 
Table 1. Distance and time taken to reach the closest health care provider of each category from the households ( $n=1200$ households).

\begin{tabular}{|c|c|c|c|c|c|}
\hline \multirow[t]{2}{*}{$\begin{array}{l}\text { Category of pro- } \\
\text { vider }\end{array}$} & & \multicolumn{2}{|c|}{$\begin{array}{l}\text { Distance to the closest health care provider } \\
(\mathrm{km})\end{array}$} & \multicolumn{2}{|c|}{$\begin{array}{l}\text { Time taken to reach the } \\
\text { closest health care provider } \\
\text { (hours) }\end{array}$} \\
\hline & $\begin{array}{l}\text { Households } \\
\text { responded }^{\mathrm{a}}\end{array}$ & Min/Max & Mean (SD) & Min/Max & Mean (SD) \\
\hline $\begin{array}{l}\text { Private -Ayurveda / } \\
\text { Traditional }\end{array}$ & 1164 & $0.01-30$ & $3.18(3.45)$ & $0.01-6.0$ & $0.50(0.4)$ \\
\hline State-Ayurveda & 1191 & $0.01-30$ & $5.71(4.74)$ & $0.01-6.25$ & $0.69(0.44)$ \\
\hline Private -Western & 1199 & $0.01-35$ & $3.10(2.88)$ & $0.02-5.0$ & $0.49(0.37)$ \\
\hline State -Western & 1200 & $0.1-35$ & $4.86(3.52)$ & $0.05-7.0$ & $0.64(0.48)$ \\
\hline Ritualistic healer & 1054 & $0.01-14.4$ & $1.24(1.52)$ & $0.01-5.0$ & $0.34(0.3)$ \\
\hline
\end{tabular}

${ }^{a}$ Only the households able to provide the information is included

Table 2 Distance to the most frequently visited healthcare facility during the six months preceding the study by members of household ( $n=1200$ households)

\begin{tabular}{rccc}
\hline \multicolumn{1}{c}{ Category of provider } & & $\begin{array}{c}\text { Distance traveled to reach health care provider } \\
(\mathrm{km})\end{array}$ \\
\hline & No of households & Min/Max & Mean (SD) \\
Private -Ayurveda /Traditional & 15 & $0.1-60$ & $8.77(15.44)$ \\
State-Ayurveda & 14 & $1.0-50$ & $9.10(12.33)$ \\
Private -Western & 355 & $0.01-100$ & $5.22(10.07)$ \\
State -Western & 787 & $0.01-125$ & $6.20(8.95)$ \\
\hline Ritualistic healer & 2 & $4.0-5.0$ & $4.5(0.70)$ \\
\hline
\end{tabular}

Table 3 Cost incurred by a patient for the visit by type of the facility ${ }^{a} \quad(n=2221$ patients)

\begin{tabular}{|c|c|c|c|c|c|c|c|}
\hline $\begin{array}{l}\text { Type of } \\
\text { facility }\end{array}$ & & Transport & $\begin{array}{c}\text { Investiga- } \\
\text { tions }\end{array}$ & $\begin{array}{l}\text { Provider } \\
\text { fees }\end{array}$ & $\begin{array}{l}\text { Additional } \\
\text { drugs/ } \\
\text { supplies }^{\mathrm{c}}\end{array}$ & Incidental $^{\mathrm{d}}$ & Total cost \\
\hline & $\begin{array}{l}\text { No of pa- } \\
\text { tients }\end{array}$ & $\begin{array}{l}\text { Median } \\
(\min / \max )\end{array}$ & $\begin{array}{l}\text { Median } \\
(\min / \max )\end{array}$ & $\begin{array}{l}\text { Median } \\
(\min / \max )\end{array}$ & $\begin{array}{l}\text { Median } \\
(\min / \max )\end{array}$ & $\begin{array}{l}\text { Median } \\
(\min / \max )\end{array}$ & $\begin{array}{l}\text { Median } \\
(\min / \max )\end{array}$ \\
\hline $\begin{array}{l}\text { Private - } \\
\text { Ayurveda / } \\
\text { Traditional } \\
\text { (PA) }\end{array}$ & 153 & $\begin{array}{l}36 \\
(0-800)\end{array}$ & - & $\begin{array}{l}130 \\
(20-430)\end{array}$ & $\begin{array}{l}72.50 \\
(10-1200)\end{array}$ & $\begin{array}{l}40 \\
(12-100)\end{array}$ & $\begin{array}{l}224 \\
(0-1500)\end{array}$ \\
\hline $\begin{array}{l}\text { State- } \\
\text { Ayurveda } \\
\text { (SA) }\end{array}$ & 346 & $\begin{array}{l}24 \\
(0-890)\end{array}$ & - & - & $\begin{array}{l}20 \\
(10-200)\end{array}$ & $\begin{array}{l}30 \\
(5-50)\end{array}$ & $\begin{array}{l}30 \\
(0-1090)\end{array}$ \\
\hline $\begin{array}{l}\text { Private - } \\
\text { Western } \\
(\mathrm{PW})\end{array}$ & 676 & $\begin{array}{l}20 \\
(0-500)\end{array}$ & $\begin{array}{l}100 \\
(50-700)\end{array}$ & $\begin{array}{l}100 \\
(20-650)\end{array}$ & $\begin{array}{l}80 \\
(3-800)\end{array}$ & $\begin{array}{l}30 \\
(15-103)\end{array}$ & $\begin{array}{l}180 \\
(0-1000)\end{array}$ \\
\hline $\begin{array}{l}\text { State- } \\
\text { Western } \\
(\mathrm{SW})\end{array}$ & 1046 & $\begin{array}{l}16 \\
(0-214)\end{array}$ & $\begin{array}{l}90 \\
(24-400)\end{array}$ & - & $\begin{array}{l}30 \\
(2-180)\end{array}$ & $\begin{array}{l}25 \\
(3-100)\end{array}$ & $\begin{array}{l}22 \\
(0-410)\end{array}$ \\
\hline
\end{tabular}

\footnotetext{
${ }^{\text {a }}$ Cost are given in Sri Lankan Rupees

${ }^{\mathrm{b}}$ Number of patients incurred additional investigations costs (PW-55, SW -11)

${ }^{\mathrm{c}}$ Number of patients incurred additional drugs/supplies costs (PA-48, SA-31, PW-242, SW-202)

${ }^{\mathrm{d}}$ Number of patients incurred incidental costs (PA-31, SA-96, PW-43, SW-259)
} 
the phenomenon of bypassing the closest health facility occur in out patient services. This phenomenon was common to all types of healthcare facilities. Hence, it was evident that providing healthcare facilities closer to households alone would not improve access to such facilities unless the issue of bypassing is adequately addressed. Resources spent on maintaining a widely distributed provider network is unlikely to be justified in the long run if some facilities are over utilized while many others are underutilized. The possibility of rationing of services in healthcare due to increased demand in Sri Lanka is already documented (18). The phenomenon of bypassing a closer facility to attend a more distance one could further increase the demand on certain facilities, thus leading to rationing of services. Apart from rationing of services deterioration in quality of services could follow.

The cost incurred in private health services was many times higher than the state health services. Although the distance to the state Western facility is $56 \%$ higher at mean values compared to the private Western facilities, actual difference is only $1.76 \mathrm{Km}$. Thus, it would be reasonable to assume that cost of care would likely to shift communities away from the private sector. To the contrary, one third of the population visited private institutions more frequently than the free of charge state facilities. As Russell pointed out, building a relationship with a particular doctor over a period of time is important for patients for continuity of care (19). In the current arrangement of state facilities in Sri Lanka, it is not possible to build up a trust relationship with a particular provider. No mechanism exists to designate a practitioner to follow up a group of patients for continued care in a primary care setting. However, the private practitioners enjoy that opportunity to function as the "family doctor" of a household. On the other hand quality of services at the OPD in the state institutions particularly relating to client satisfaction was low (20). Hence, the perception of improved quality of private sector healthcare services increases the likelihood of those facilities being chosen despite the deterrent affect of high cost (17). Furthermore, out patient departments in state hospitals operates from 8.00 am to $4.00 \mathrm{pm}$ while the facilities are closed on Saturday evenings and Sundays. As most Western private facilities operate as part time practices of government doctors, they functions after hours when state facilities are closed. Difference in the functioning hours of two types of facilities is also likely to play a role on the differential access to state and private healthcare facilities.

As mentioned above state health services were claimed to be free of charge at the point of delivery. Patients did not have to pay for the physician service, supplies or for investigations done at the state facilities in both Western and Ayurveda / traditional systems. However, as shown in the Table 3 it was evident that consumers who opted for the free health services offered by the government had to bear substantial costs in seeking treatment from the state facility. Many patients had to bear the cost of investigations and additional drugs / supplies prescribed by the state facilities that had to be purchased in the private sector. This suggests that although the physician services were free of charge, patients had to bear a part of the direct medical cost themselves. On the other hand transport cost and incidental cost, mostly on food, was indirectly related to the distance traveled to reach the facility and the time spent on the visit. Hence, the factors that propagate the bypass phenomenon of closer facilities in search for more distant ones which were related to the health system itself could be held at least partly accountable for this additional expenditure on treatment seeking. Therefore, the background costs in seeking treatment in a state facility deflate the true meaning of the "free of charge" services. Poverty statistics indicated that $27.5 \%$ of households in Kegalle district lived below the official poverty line of Sri Lanka (21). Considering the economic back ground of the population it is likely that healthcare cost may act as a deterrent for using services even in state facilities.

Waxler (22) observed that western biomedicine was well established in Sri Lanka while Ayurveda flourishes as large proportion of population used and believed it to be effective. However, this study pointed that even in the rural sector less than $5 \%$ of households frequently utilized Ayurveda / traditional treatment. Consumer finance and socioeconomic survey of Sri Lanka had also predicted a decline in the usage of non western healthcare facilities (23). This suggests a paradigm shift from a plural healthcare system towards a singular dominant system in Sri Lanka. High costs for Ayurveda drugs / supplies and substantial transport costs coupled with incidental costs due to gross underutilization of village level providers amounts to higher total cost for a visit compared to Western healthcare facilities. The shift of communities from Ayurveda /traditional healthcare, points to increasing demand for Western healthcare that leads to further rationing of services. Apart from the direct impact on healthcare, underutilization of Ayurveda / tradition care also suggests movement away from the existing cultural ideologies. Kleinman (24) proposed that health systems are articulated as cultural systems. Hence, disappearance of certain health systems may also challenge underline cultural norms that leads to further polarization of the health seeking behavior patterns and having negative consequences towards access to healthcare.

The evidence suggests that the policy makers and implementers in Sri Lanka need to examine the current provisions of healthcare services in terms of accessibility and affordability. As shown earlier, availability of wide network of facilities and notion of free services at the point of delivery in the state sector does not necessarily mean that the issues of accessibility and affordability are adequately 
addressed. There is enough room for improvement. Measures are needed to optimize the utilization of existing services while reducing the financial burden on the consumer and the health system.

In order to reduce the out of cost expenditure in seeking treatment, alternative options for healthcare financing need to be pursued. Only a small proportion of non governmental funding is coming from employers, commercial insurance and non profit organizations at present (4). It is unrealistic to expect a substantial involvement of those sectors in sharing healthcare spending in the near future. Hence, increased allocation and efficient distribution of government resources in the health sector would be vital to maintain the improvements achieved in the health status of the population during the last four decades in the country. Developing essential service packages, optimal utilization of exiting healthcare facilities, creating a local level family practitioner network for primary care, adherence to treatment guidelines to minimize wastage on drugs / supplies and investigations, redefining the opening hours of state facilities and regulatory process to streamline the private sector healthcare institutions would have a positive impact on the financial burden particularly on rising out of pocket expenditure on healthcare.

Absence of a referral system in both state and private sector has influenced phenomenon of bypassing. This has caused mal utilization of facilities leading to rationing of services and unnecessary financial burden on the consumer. Introduction of a strict referral system would curtail the trend of bypassing the nearest facility particularly for minor illnesses that can be managed at local clinics. Cross referral mechanism between state / private and between Western / Ayurveda - traditional would facilitate better utilization of facilities and providing the clients more options and better access to healthcare.

It is estimated that 16000 Ayurveda / traditional practitioners are in the country and only a fraction of them practicing regularly (25). Utilizing this readily available human resource in catering to primary care at village level would ease the burden on the state run health facilities and improving the access to healthcare (26). Proper training opportunities and systematic registration system of practitioners would likely to enhance their recognition in the community, thus improving utilization.

\section{Conclusion}

This paper explored access to healthcare in terms of physical proximity to the provider and the affordability of such services. The paper suggests that physical proximity of facilities and free of charge status of state health care services per se does not guarantee their utilization. It also indicated the possibility of transition from medical pluralism to a single dominant system of healthcare in the country and how would it affect access to healthcare. Finally, the paper focused attention on possibilities to be considered in future policy discussions on healthcare reforms in Sri Lanka.

\section{Acknowledgements}

We are grateful to Dr. Robert M Goodman, Dean, School of Health, Physical Education and Recreation, University of Indiana, USA for his valuable comments on the draft. The study was supported by the HSRU, Faculty of Medicine, University of Colombo Sri Lanka. 


\section{References}

1. Caldwell, J., Gajanayake, I., Caldwell, P., Peiris, I. Sensitization to illness and the risk of death: an explanation for Sri Lanka's approach to good health for all. Social Science and Medicine. 28 (4): 365-379, 1989

2. Uragoda, C.G. A History of Medicine in Sri Lanka. Sri Lanka Medical Association, Colombo, 1987.

3. Obeysekere, G. The impact of Ayurvedic ideas on the culture and the individual in Sri Lanka. In Asian medical system: A comparative study, ed. C. Leslie, pp. 201-226. University of California press, Berkeley, 1976.

4. Institute of Policy Studies. Sri Lanka National Health Accounts 2003-2004. Institute of Policy studies, Colombo, in press.

5. World Health Organization. Macroeconomics and health: investing of health for economic development. Report of the commission on macroeconomics and health. World Health Organization, Geneva, 2001.

6. Nichter, M. The layperson's perception of medicine as perspective into the utilization of multiple therapy systems in Indian context. Social Science and Medicine 14B: 225-233, 1980.

7. Ministry of Health Sri Lanka. Annual Health Bulletin 2003. Ministry of Health Sri Lanka, Colombo, 2004.

8. Wanninayaka, P.B. Ayurveda in Sri Lanka. Ministry of Health Sri Lanka, Colombo, 1982.

9. Ariyasena, U.M.G. Involvement of traditional medical practitioners in Primary Health Care Thesis (MD). Postgraduate Institute of Medicine, Colombo, 1989.

10. Obeysekere, G. 1977. Psychocultural Exegesis of a case of sprit possession in Sri Lanka. In Case studies in sprit possession, ed. V. Crapanzano and V. Garrison, pp. 235-294. J.Wiley, New York, 1977.

11. Wijesekera, N. Deities and Demons Magic and Masks. Gunesena, Colombo, 1987.

12. Amarasingham, L. Movement among healers in Sri Lanka: A case study of Sinhalese patient. Culture, Medicine and Psychiatry 4: 72-92, 1980.

13. Ministry of Health and Nutrition. Health Master Plan, Healthy and Shining Island in the $21^{\text {st }}$ Century. Volume 1, Ministry of Health and Nutrition, Colombo, 2007.

14. Lwanga, S.K., Lemeshow, S. Sample size determination in health studies. World health Organization, Geneva, 1991.

15. Moser, C.A., Kalton, C. Survey methods in social investigation. Heinemann, London, 1971.

16. Simenov, L.A. Better Health for Sri Lanka, Report on a Health Manpower study. World Health Organization Regional Office for South-East Asia, Delhi, 1975.

17. Akin, J.S., Hutchinson, P. Health-care facility choice and phenomenon of bypassing. Health Policy and Planning 14(2):135-151, 1999.
18. Withanachchi, N., Uchida, Y. Healthcare ra tioning: A guide to policy directions in Sri Lanka. Health Policy 78: 17-25, 2006.

19. Russell, S. Treatment-Seeking behaviour in urban Sri Lanka: Trusting the state, trusting private providers. Social Science and Medicine, 61:1396-1407, 2005.

20. Ministry of Health, Sri Lanka and Japan International Agency. Master Plan study for the Strengthening of Health System in Democratic Socialist Republic of Sri Lanka, Supporting Document 11, Survey on health service delivery, Healthy and Shining Island in the $21^{\text {st }}$ Century, Final Report. Pacific Consultants International, Colombo, 2003.

21. Department of Census and Statistics, Sri Lanka. Official poverty line for Sri Lanka 2004. http://www.statistics.gov.lk/poverty/ index.htm (October 4, 2005).

22. Waxler, N.E. Behavioural convergence and institutional separation: An analysis of plural medicine in Sri Lanka. Culture, Medicine and Psychiatry 8: 187-205, 1984.

23. Central Bank of Sri Lanka. Consumer Finance and Socio Economic Survey 2003/04. Central Bank of Sri Lanka, Colombo, 2005.

24. Kleinma, A. Concepts and a model for the comparison of medical systems as cultural systems. Social Science and Medicine 12: 85-93, 1978.

25. Ministry of Health, Sri Lanka and Japan International Agency. Master Plan study for the Strengthening of Health System in Democratic Socialist Republic of Sri Lanka, Healthy and Shining Island in the $21^{\text {st }}$ Century. Final Report, Situation Analysis, Vol. 2. Pacific Consultants International, Colombo, 2003.

26. World Health Organization. Primary Healthcare and health for all by 2000. Alma-Ata conference. World Health Organization, Geneva, 1979. 